\title{
PEMANFAATAN SAMPAH BERNILAI EKONOMIS, PENYULUHAN PEMANFAATAN SAMPAH MENJADI KOMPOS DENGAN METODE TAKAKURA DI DESA BALE KAMBANG KECAMATAN MANCAK KABUPATEN SERANG
}

\author{
Ade Millatus Sa'adiyyah \\ Universitas Banten Jaya, J1 Syech Nawawi Albantani Serang, Banten, Indonesia \\ E-mail: ademillatussa’adiyyah@unbaja.ac.id
}

\begin{abstract}
The aim of the Community Service Program Community Work and Community Empowerment Study Program (KKN-PPM) is to provide counseling to residents of Bale Kambang Village, Mancak District, Serang Regency. The problem faced in Bale Kambang Village is about rubbish, rubbish produced from households and plants around the house, ie the community does not know about processing to compost using the Takakura method so that it can ultimately increase community productivity and well-being that has value selling. The methods of implementing this service are (1) survey through initial observation, problem analysis, interviews, and documentation. (2) Counseling for composting using the Takakura method. This community service program is expected to provide additional knowledge to the community and to provide added value about composting using the Takakura method which is very simple and can have selling points to increase the welfare of the community, so that Bale Kambang Village in Mancak District can be made into a clean village and its people are clean. skilled and have high productivity.
\end{abstract}

Keywords: Garbage, Takakura, Compost.

\begin{abstract}
Abstrak
Tujuan Program Pengabdian Masyarakat Kuliah Kerja Nyata Pembelajaran dan Pemberdayaan Kepada Masyarakat (KKN-PPM) adalah melakukan penyuluhan terhadap warga masyarakat Desa Bale Kambang Kecamatan Mancak Kabupaten Serang. Permasalahan yang di hadapi di Desa Bale Kambang adalah mengenai sampah, sampah yang dihasilkan dari rumah tangga dan tanaman yang ada di sekitar rumah, yaitu masyarakat belum mengetahui mengenai pengolahan sampai menjadi kompos menggunakan metode Takakura sehingga akhirnya dapat menambah produktifitas masyarakat dan juga kesejahteraan yaitu memiliki nilai jual. Metode pelaksanaan pengabdian ini yaitu (1) survey melalui pengamatan awal, analisis permasalahan, wawancara, dan dokumentasi. (2) Penyuluhan pembuatan kompos dengan menggunakan metode Takakura. Program pengabdian ini diharapkan dapat memberikan pengetahuan tambahan untuk masyarakat dan untuk memberikan nilai tambah tentang pembuatan kompos dengan menggunakan metode Takakura yang sangat sederhana dan dapat memiliki nilai jual guna menambah kesejahteraan masyarakat, sehingga Desa Bale Kambang Kecamatan Mancak dapat di jadikan desa yang bersih dan masyarakatnya yang terampil dan memiliki produktifitas tinggi.
\end{abstract}

Kata Kunci : Sampah, Takakura, Kompos

\section{PENDAHULUAN}

Kelurahan Bale Kambang merupakan salah satu daerah yang strategis untuk mengembangkan dan meningkatkan taraf hidup yang sejahtera. Hal ini dapat terlihat dari beraneka ragamnya jenis usaha atau pekerjaan yang mereka miliki. Letak Kelurahan Bale Kambang Kecamatan Mancak Kabupaten Serang yaitu terletak 5.6 Km jarak dari pemerintahan Kecamatan Mancak, 25 Km jarak dari pusat pemerintahan Kabupaten Serang, 38 Km jarak dari pusat Pemerintahan Provinsi Banten, adapun batas Kelurahan Bale Kambang Kecamatan 
Mancak Kabupaten Serang adalah sebagai berikut : Sebelah utara berbatasan dengan Kelurahan Sigedong. Sebelah selatan berbatasan dengan Kelurahan Angsana.Sebelah barat berbatasan denganKelurahan Labuan.Sebelah timur berbatasan dengan Kelurahan Talaga. Luas Kelurahan Bale Kambang Kecamatan Mancak Kabupaten Serang adalah 425.29 Ha yang terbagi dalam beberapa kategori peruntukan lahan tersebut. Penggunaan Lahan untuk pemukiman sekitar 100 $\mathrm{Ha}$, pertanian $328.74 \mathrm{Ha}$, sisanya adalah prasarana umum. ( sumber : data kelurahan Bale Kambang ). Luas Kelurahan Bale Kambang Kecamatan Mancak Kabupaten Serang adalah 425.29 Ha yang terbagi dalam beberapa kategori peruntukan lahan tersebut. Penggunaan Lahan untuk pemukiman sekitar $100 \mathrm{Ha}$, pertanian $328.74 \mathrm{Ha}$, sisanya adalah prasarana umum. (sumber : data kelurahan Bale Kambang). Luas Kelurahan Bale Kambang Kecamatan Mancak Kabupaten Serang adalah 425.29 Ha yang terbagi dalam beberapa kategori peruntukan lahan tersebut. Penggunaan Lahan untuk pemukiman sekitar $100 \mathrm{Ha}$, pertanian $328.74 \mathrm{Ha}$, sisanya adalah prasarana umum. ( sumber : data kelurahan Bale Kambang ).

Perekonomian menjadi factor yang sangat mempengaruhi kehidupan masyarakat Desa Bale Kambang memiliki beberapa usaha diantaranya : ladang sawah, perkebunan melinjo dan bambu, ladang yang mana itu adalah sebagian sumber mata pencaharian warga Desa Bale Kambang. Karena banyak masyarakat menjual barang mentah sehingga harganya murah sehingga mempengaruhi pendapatan warga desa yang rendah juga.

Berdasarkan dari pengamatan dan hasil wawancara dengan masyarakat Bale Kambang, di Desa Bale Kambang belum tersedianya tempat pembuangan akhir sampah di desa, akhirnya sampah yang dihasilkan dari kegiatan masyarakat sehari-hari hanya dibuang begitu saja di halaman rumah warga atau juga dengan cara dibakar. Oleh karena itu, dalam kegiatan KKMPPM bertujuan untuk meningkatkan pengetahuan dan keterampilan masyarakat desa Bale Kambang Kecamatan Mancak Kabupaten bahwa sampah yang biasanya hanya dibuang begitu saja, ternyata bisa dimanfaatkan dan menghasilkan rupiahn yang cukup menguntungkan. Jika dikelola dengan baik, sampah-sampah yang berserakan dan membuat kotor lingkungan bisa memberikan dampak yang baik bagi masyarakat dan lingkungan itu sendiri. Berangkat dari permasalahan tersebut, KKM-PPM berupaya membuat penyuluhan agar menumbuhkan kesadaran peduli terhadap lingkungan dan bisa memanfaatkan sampah supaya menjadi barang yang bernilai tinggi.

Teknologi tepat guna yang bisa diterapkan yaitu Takakura yang merupakan proses kompos skala rumah tangga dengan bantuan sampah organik. Jadi, masyarakat bisa mengelola sendiri sampahnya dengan bibit fermentasi dan bibit yang dibuat dengan sederhana dan biaya yang sangat minim. 


\section{METODE}

Metode yang digunakan dalam kegiatan ini adalah (1) pembekalan terhadap mahasiswa KKM Kelompok 7 Universitas Banten Jaya (Unbaja) yang dilaksanakan di posko mahasiswa KKM kelompok 7 (2) pelaksanaan pengabdian di Desa Bale Kambang dilaksanakan pada hari Rabu, tanggal 21 Agustus 2019 diawali dengan pemberian materi mengenai memanfaatkan sampah menjadi barang bernilai ekonomis melalui Penyuluhan Bank Sampah. (3) pelaksanaan di lakukan di Desa Bale Kambang, Kecamatan Mancak dengan penyuluhan Bank Sampah tersebut di Kantor Balai Desa Bale Kambang, Kecamatan Mancak. Menghadirkan pemateri Ricky Febriyanto, S.Si,.M.Si (4) Demonstrasi pembuatan kompos dengan menggunakan teknologi tepat guna takakura (5) Praktek pembuatan takakura dengan bimbingan Tim KKM PPM dan mahasiswa pendamping.

\section{Alat, Bahan dan Diagram Alur Pembuatan Takakura.}

a. Alat

Alat utama yang digunakan dalam proses pembuatan kompos dengan metode Takakura adalah dalam Tahap Proses Pengomposan Alat-alat yang di gunakan :

1. Sekop atau cangkul

2. Keranjang takakura

\section{b. Bahan}

Bahan - bahan yang digunakan adalah jenis-jenis Sampah untuk Kompos Sampah Organik yaitu sampah yang dapat membusuk seperti Sisa makanan, sayuran, buah-buahan dan dedaunan.

1. Bahan yang digunakan adalah Sampah Rumah Tangga (Organik)

2. Starter Kompos

3. Bantalan sekam dua buah/bantalan dari serabut kelapa

4. Air secukupnya.

\section{c. Cara Pembuatan.}

Secara garis besar terdapat 4 tahapan utama dalam menerapkan metode komposting Takakura, yaitu :

1. Membuat media fermentasi,

2. Membuat bibit kompos Takakura,

3. Membuat keranjang Takakura, dan

4. Pengomposan. 
Proses Pembuatan:

a. Sampah organik dari rumah tangga dicacah terlebih dahulu sampai berukuran kecil (makin kecil cacahan makin bagus) bisa menggunakan mesin atau dicacah sendiri menggunakan peralatan dapur.

b. Siapkan keranjang takakura yang telah diisi dengan bantalan sekam/bantalan dari serabut kelapa pada bagian bawah dan starter.

c. Sampah yang telah dicacah dimasukkan ke dalam keranjang kemudian aduk dengan bahan starter dan air secukupnya

d. Tutup dengan bantalan sekam/bantalan serabut kelapa di bagian atas

e. Apabila ada sampah organik yang baru, prosesnya sama seperti sebelumnya.

f. Apabila kompos terlalu basah maka cukup diangin-anginkan, apabila terlalu kering tambahkan air secukupnya.

g. Pemanenan kompos dapat dilakukan tergantung dengan banyaknya sampah organik yang dikomposkan

h. Untuk proses pengomposan selanjutnya, Sisakan kompos tersebut sesuai dengan kebutuhan yang nanti dipergunakan untuk stater berikutnya.

Berikut adalah ciri-ciri Kompos yang bagus:

a. Berwarna gelap (Kehitam-hitaman) dan berbau seperti tanah

b. Bentuk fisik kompos tidak seperti aslinya

c. Biasanya volume kompos berkisar $25 \%-30 \%$ dari volumen sampah organik bahan kompos.

d. Suhu berkisar $30^{\circ} \mathrm{C}-35^{\circ} \mathrm{C}$

\section{d. Diagram Alur Proses Pembuatan Kompos dengan Metode Takakura}

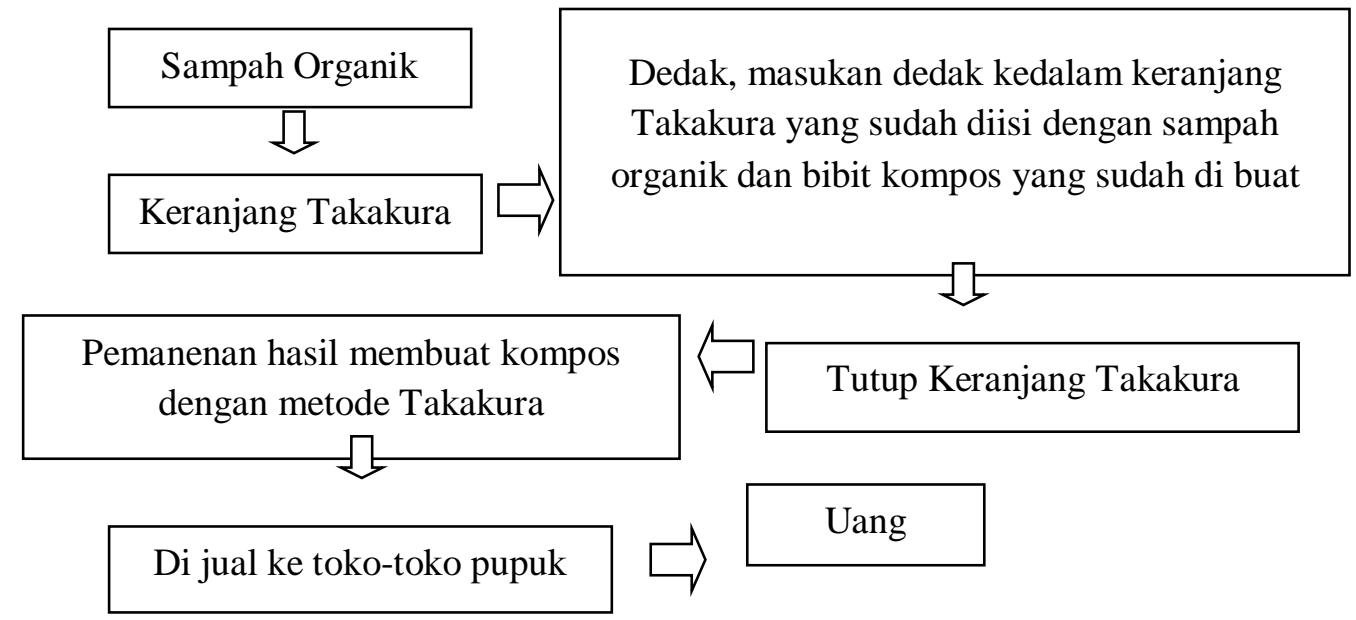

Diagram 1. Alur Proses Pembuatan Kompos 


\section{HASIL DAN PEMBAHASAN}

\section{Pembekalan kepada mahasiswa pendamping lapangan}

Kegiatan yang pertama kali dilakukan adalah pembekalan kepada mahasiswa pendamping lapangan mengenai materi pelatihan yang akan dilaksanakan di desa Bale Kambang Kec. Mancak, dalam hal ini materi yang disampaikan mengenai pengolahan sampah rumah tangga menjadi kompos Takakura.

Kegiatan ini dilaksanakan di Universitas Banten Jaya, Kampus 1 Jl. Ciwaru II No. 73 Kota Serang - Banten Kegiatan oleh Bapak Ricky Febriyanto,.S.Si,.M.Si Dosen Teknik Lingkungan Universitas Banten Jaya.

\section{Pelaksanaan pelatihan}

Pemberian materi mengenai proses pembuatan kompos dengan menggunakan metode Takakura dan cara pembuatannya, pengenalan nama-nama bahan yang digunakan. Kegiatan selanjutnya yaitu pelaksanaan KKN-PPM di Desa Bale Kambang kec. Mancak.

Kegiatan selanjutnya adalah pelaksanaan KKM-PPM di Desa Bale Kambang dengan tema 'Sampah = Rupiah'. Kegiatan dilaksanakan pada hari Rabu Tanggal 21 Agustus 2019.

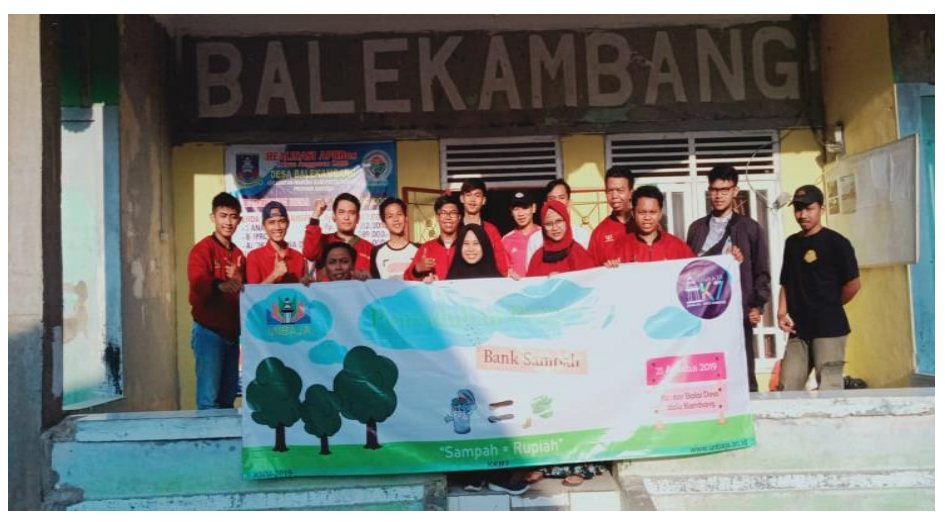

\section{Gambar 1. Persiapan Pelaksanaan Pengabdian di Aula Desa Bale Kambang}

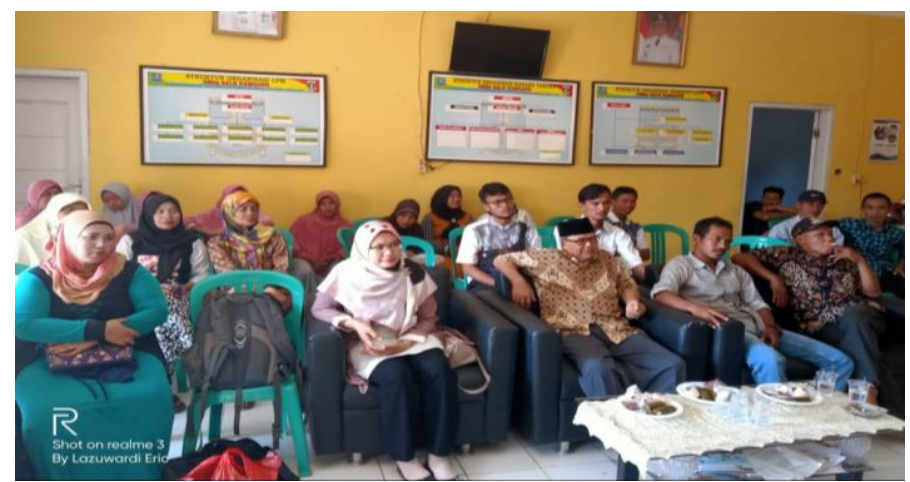

Gambar 2. Pelaksanaan Pelatihan di Aula Desa Bale Kambang. 


\section{Demonstrasi Pembuatan pembuatan pupuk dengan metode Takakura.}

Kegiatan ke tiga adalah demonstrasi nara sumber yaitu Bapak Ricky Febrianto dengan mahasiswa pendamping serta Tim dosen KKN-PPM . kegiatan ini juga di isi dengan diskusi tanya jawab antara nara sumber dan masyarakat yang hadir di Balai Desa Bale Kambang, antara lain masyarakat bertanya mengenai bahan-bahan yang digunakan dalam pembuatan kompos dengan metode Takakura ini dan proses pembuatannya.

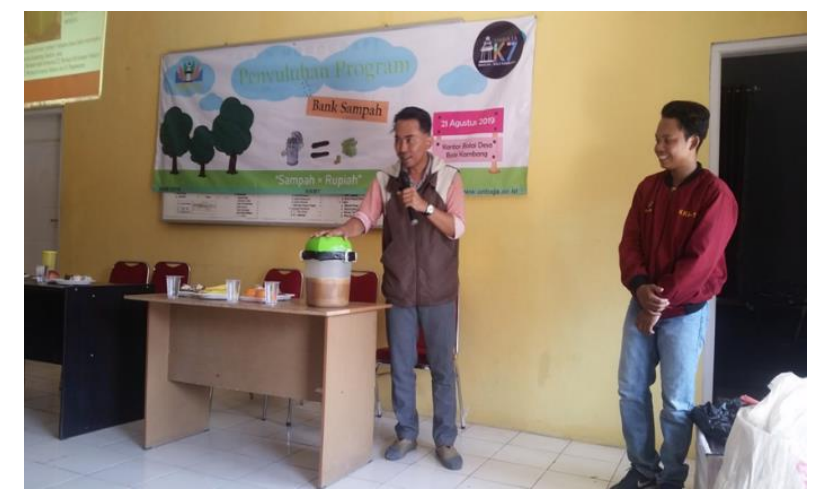

Gambar 3. Pelaksanaan Pembuatan Bibit Kompos

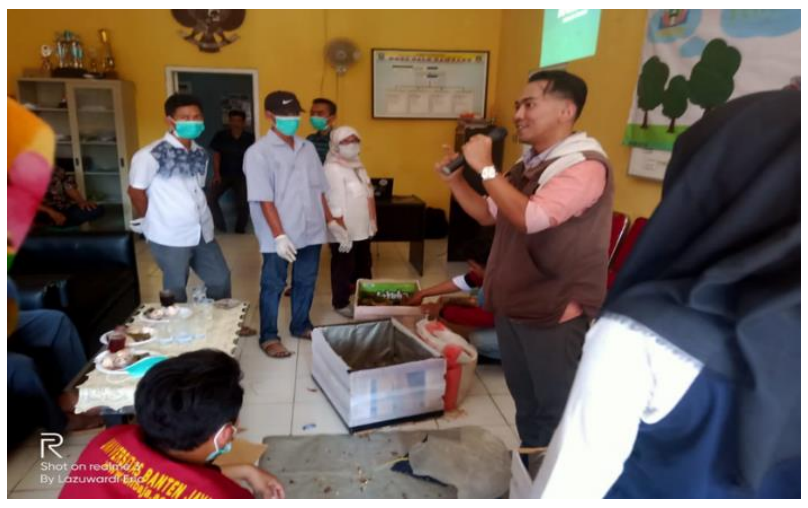

Gambar 4. Pelaksanaan Praktek Pembuatan Kompos dengan Metode Takakura.

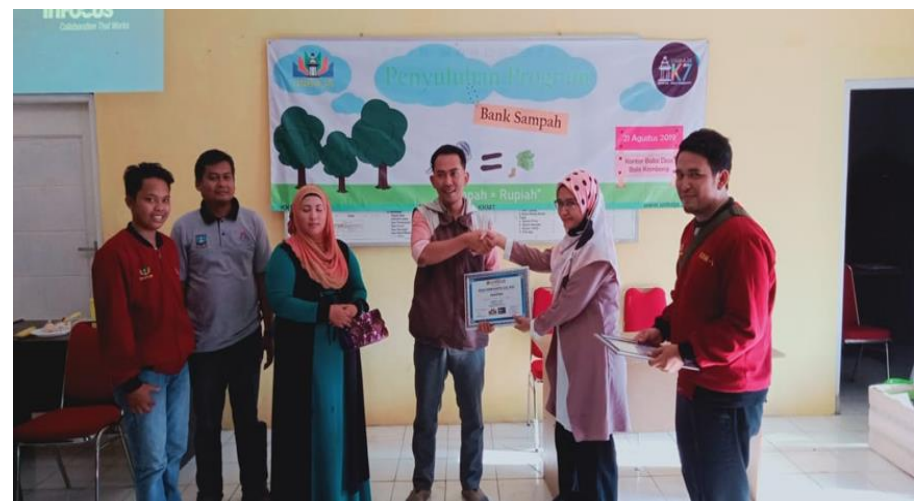

Gambar 5. Pemberian sertifikat kepada nara sumber. 


\section{KESIMPULAN}

Teknologi tepat guna yang bisa diterapkan yaitu Takakura yang merupakan proses kompos skala rumah tangga dengan bantuan sampah organik. Jadi, masyarakat bisa mengelola sendiri sampahnya dengan bibit fermentasi dan bibit yang dibuat dengan sederhana dan biaya yang sangat minim.

Tujuan dari Penyuluhan KKM-PKM kepada masyarakat Desa Balekambang agar mereka punya gambaran bagaimana cara pengelolaan teknologi tepat guna pembuatan kompos dengan metode Takakura yang bisa diterapkan di Desa Bale Kambang Kec.Mancak agar masyarakat bisa mengurangi hasil sampah dari rumah yang ada di Desa Bale Kambang dan juga dapat menghasilkan nilai ekonomis di pasaran. Dan juga agar sampah-sampah di desa bisa dikelola dengan baik. Dengan kegiatan ini diharapkan mayrakat Desa Bale Kambang Kec. Mancak dapat keterampilan dalam membuat kompos Takakura dan bisa meningkatkan kreatifitas dan produktifitas yang dapat menghasilkan tambahan untuk kesejahtraan masyarakat.

\section{UCAPAN TERIMAKASIH}

Ucapan terimakasih disampaikan kepada :

1. Kepala Desa Bale Kambang Kec.Mancak yang telah bekerja sama dan memberikan kesempatan untuk dapat melakukan pengabdian di desa tersebut.

2. Dosen Pembimbing dan Nara Sumber Tim Takakura Universitas Banten Jaya yang telah bekerja sama dalam pelaksanaan kegiatan KKN-PPM sebagai Tutor dalam penyuluhan pembuatan kompos dengan metode Takakura ini.

\section{DAFTAR PUSTAKA}

Panduan Penelitian dan Pengabdian Kepada Masyarakat edisi XII, Direktorat Riset dan Pengabdian Masyarakat, Direktorat Jenderal Penguatan Riset dan Pengembangan, Kementerian Riset, Teknologi dan Pendidikan Tinggi tahun 2018.

Isro. (2018). Kompos.makalah. Balai Penelitian BIO Teknologi Perkebunan Indonesia, Bogor, Kompos,Limbah Padat Organik.

Cecep Dani Sucipto, Teknologi Pengolahan Daur Ulang Sampah, Jakarta, Goysen, Publishing, 2009.

Alex S, Sukses Mengolah Sampah Organik Menjadi Pupuk Organik, Yogyakarta, Pustaka Baru Press. 